\title{
Nanomaterials for the Adsorptive Removal of Antibiotics from Aqueous Solution: A Minireview
}

\author{
Jamiu. O. Eniola, ${ }^{a}$ Rajeev Kumar, ${ }^{*, a}$ and M. A. Barakat ${ }^{a, b}$ \\ ${ }^{a}$ Department of Environmental Sciences, Faculty of Meteorology, Environment and Arid Land Agriculture, \\ King Abdulaziz University, Jeddah 21589, Saudi Arabia \\ ${ }^{b}$ Central Metallurgical R \& D Institute, Helwan 11421, Cairo, Egypt \\ Email: olifiaraju@gmail.com (R. K.)
}

\begin{abstract}
In the last decade, researchers discovered the existence of new type of emerging pharmaceutical pollutants such as drugs, personal care products, hormones, and so on, in wastewater as well as drinking water. These contaminants are hard to remove using conventional treatment technology. The use of advanced nanomaterials-based technologies for the treatment of emerging contaminants from wastewater and drinking are gaining much attention from the researchers. Adsorption is one of the wastewater treatment methods for the decontamination of wastewater. Herein, the applications of a variety of pure materials as well as nanocomposite materials are summarized used for adsorptive removal of antibiotics. The role of different functional groups and adsorption forces are discussed.
\end{abstract}

Keywords adsorption, antibiotics, mechanism, wastewater purification

\section{Introduction}

In the last decade, occurrence of xenobiotic compounds such as pesticides, pharmaceuticals, drugs and endocrinedisrupting organics in wastewater streams has been skeptically observed. ${ }^{[1]}$ Special interest has been given to pharmaceutical wastewater, containing organics which are not entirely roofed by the current legislation in the field of water quality. These organic chemicals are potentially harmful to ecosystems and humans. Such compounds are termed as emerging contaminants (ECs). Very few studies have reported the harmful effect of ECs. These studies suggested that ECs are carcinogenic and may affect the physiology, reproduction, growth, and the endocrine system in wild species. ${ }^{[2]}$ The existence of ECs can be found in the drinking water in a meager amount $(10 \mu \mathrm{g} / \mathrm{L}$ to $20 \mu \mathrm{g} / \mathrm{L}){ }^{[3,4]}$ Current treatment technologies are not quite efficient to treat wastewater containing ECs.

Pharmaceutical products enter the environment by a variety of sources, but wastewater treatment plants (WWTP) are the major spot of their storage and discharge into the environment. Generally, wastewater treatment plant is designed to remove solid, suspended, organic, inorganic, and biological matter and unable to complete removal of such persistent ECs. Therefore, alternative new technologies for the scavenging of ECs from wastewater are necessary.

Recently, there has been extensive research for developing advanced water treatment technologies to overcome the aforementioned issues. They include membrane filtration, adsorption, reverse osmosis, ion-exchange, and advanced oxidation processes (AOPs) using electron beam, ultraviolet radiation, photocatalysis, oxidants $\left(\mathrm{O}_{3}\right.$ or $\left.\mathrm{H}_{2} \mathrm{O}_{2}\right)$, ultrasound. ${ }^{[4,5]}$ Current treatment technologies are not quite efficient to treat wastewater containing ECs. Adsorption has been considered as a powerful technology for the removal of persistent organic compounds because of the strong binding ability of adsorbents for the pharmaceuticals. The significant advantages of the adsorption are low cost, easy handling, and reusability of the adsorbents materials. A variety of adsorbents based on carbons, clays, minerals, metal oxides, polymers, industrials and agricultural by-products, and so forth, have been reported in the literature for the removal of organic, inorganic and biological contaminants..$^{[2,5-11]}$ In last decade, nanomaterials such as carbon nanotubes, graphene oxide and metal oxides are widely explored for the removal of variety of the pollutants. The properties of the nanomaterials such as small size, large surface area and easy modification make them the efficient materials for the adsorption applications. ${ }^{[5-9,11]}$ However, adsorption of antibiotics has not been explored in comparison to the other type of pollutants such as dyes, heavy metals, and volatile organic components.

This review is focused on the adsorptive removal of the antibiotics using a variety of adsorbents based on polymers, carbon, minerals, etc.

\section{Adsorptive Removal of Antibiotics}

Adsorption is a surface phenomenon and depends on properties of an adsorbent such as surface area, presents functional groups on the surface, surface charge, etc. However, the nature of adsorbate and experimental conditions also control the adsorption process. Nanomaterials have received growing attention from scientists due to the unique functionality and superior features such as high surface area, high stability, and small size. It was demonstrated that nanomaterials play essential roles in the adsorptive removal of antibiotics from aqueous. ${ }^{[53]}$ Herein, we focused on some class of the adsorbent materials used for the removal of antibiotics.

\section{Polymeric adsorbents}

Polymeric adsorbents have been emerging as potential alternatives for the other conventional adsorbents such as the activated carbon due to its high regeneration, selectivity, higher surface area, and adjustable surface chemistry under mild conditions. Polymeric adsorbents have been studied to remove several organic pollutants ${ }^{[12]}$ and trace pollutants $\mathrm{s}^{[13]}$ from water. They are synthesized by the deposition of inorganic nanoparticles (e.g., metal oxides) on a desired polymeric support. ${ }^{[14]}$ 
Polymer sorbents can easily be modified as ionic or hydrophobic to suit for the removal of the targeted antibiotics from water. ${ }^{[10]}$ Recently, many studies have been conducted to investigate the adsorption properties of polymeric adsorbents for the removal of antibiotics from aqueous solutions. The adsorption capacity of few polymeric sorbents for antibiotics is shown in Table 1. Zhang et al. ${ }^{[15]}$ observed that the adsorption of tetracycline on polyimide (PI)-based carbon nanofibers (CNFs) was $\mathrm{pH}$-dependent and ionic strength independent. They reported a high adsorption capacity at $\mathrm{pH} 3-7$. Moreover, the adsorption mechanism for tetracycline removal was governed majorly by non-covalent bond interaction such as electrostatic attraction or hydrophobic attraction; and also $\pi-\pi$ interactions. Belaib et al. ${ }^{[12]}$ reported the adsorption mechanism of tetracycline on polyaniline coated peanut shells to be hydrogen bond. Furthermore, Zhang et al. ${ }^{[15]}$ found that the adsorption of tetracycline on CNF was endothermic and spontaneous. Similarly, Zhang et al. ${ }^{[16]}$ found that the adsorption of oxytetracycline on cyclodextrin polymers was $\mathrm{pH}$-dependent. Hydrogen bonding and $\pi-\pi$ interaction were used to describe the adsorption mechanism of the reaction. Chaubal et al. ${ }^{[19]}$ observed that $\mathrm{pH}$ is an important factor in the removal of the antibiotics (penicillin $\mathrm{V}$, tetracycline, and cephalosporin $\mathrm{C}$ ) on commercially neutral polymeric sorbents (aromatic sorbent and aliphatic ester sorbent). Cephalosporin $\mathrm{C}$ and tetracycline had a higher affinity for the aromatic sorbent (Amberlite XAD-16) a more negative enthalpy compared to adsorption onto an aliphatic ester sorbent (Amberlite XAD-7). Considerable affinities were observed for adsorption of penicillin $\mathrm{V}$ onto the surface of the aromatic sorbent at low $\mathrm{pH}$. In a study by Ribeiro and Ribeiro, ${ }^{[17]}$ erythromycin antibiotics was adsorbed from water onto neutral (XAD-4, XAD-7, and XAD-16) and anionic resins (IRA-410). The highest adsorption capacities were observed on the neutral resins XAD-7 and XAD-16. Zhang et al. ${ }^{[51]}$ investigated the removal of oxytetracycline on two weathered microplastic of same polymer types. The results showed that the beach foams had a higher adsorption capacity in comparison to virgin foams, which is attributed to the higher surface area, micropore area, and the degree of oxidation of the former. It was observed that $\mathrm{pH}$, ionic strength, and humic acid concentration play an important role in the reaction and the effect of $\mathrm{pH}$ was more pronounced in the beach foams. The results revealed that the adsorption mechanism might be electrostatic, hydrogen bonding, $\pi-\pi$ interaction depending on the environmental condition. Similarly, Li et al. ${ }^{[18]}$ investigated the adsorption of 5 antibiotics (sulfadiazine (SDZ), amoxicillin (AMX), tetracycline (TC), ciprofloxacin (CIP), trimethoprim (TMP) on 5 types of microplastics (polyethylene (PE), polystyrene (PS), polypropylene (PP), polyamide (PA), and polyvinyl chloride (PVC).) The adsorption behavior of the five antibiotics on the microplastics indicated that the structure of the antibiotics, nature of the sorbent and environmental condition (e.g., ionic strength and $\mathrm{pH}$ ) might influence the adsorption capacity of the sorbent for the drug. For instance, it is expected that the

Table 1 Adsorption capacity of some polymer sorbents

\begin{tabular}{ccccccc}
\hline Drug & Adsorbent & $\mathrm{pH}$ & $\begin{array}{c}\text { Temp./ } \\
{ }^{\circ} \mathrm{C}\end{array}$ & $\begin{array}{c}\mathrm{BET} / \\
\left(\mathrm{m}^{2} / \mathrm{g}\right)\end{array}$ & $\begin{array}{c}\text { Ad. Cap./ } \\
(\mathrm{mg} / \mathrm{g})\end{array}$ & Ref. \\
\hline Penicillin V & XAD-16 & 2.7 & 25 & 904 & 1401 & {$[19]$} \\
Cephalexin & XAD-16 & 3 & 25 & 800 & 116 & {$[50]$} \\
Erythromycin & XAD-4 & - & 30 & 725 & 358 & {$[17]$} \\
Tetracycline & $\mathrm{CS} 15$ & - & - & - & 4.710 & {$[49]$} \\
Ciprofloxacin & $\mathrm{CS} 15$ & - & - & - & 4.413 & {$[49]$} \\
\hline
\end{tabular}

polarity, surface area, and the degree of crystallinity of the sorbent may influence their adsorption capacities. Also, the hydrophobic antibiotics had a higher affinity for PP, PS, PE, and PVC. From the discussion, PA had the strongest adsorption for the antibiotics. The main binding mechanism between sorbent and antibiotics is hydrogen bonding, hydrophobic interaction, van der Waals force, and electrostatic interaction. These examples show that environmental condition and nature of the polymeric sorbent to antibiotics may be deciding factors for the estimation of the adsorption capacity. In a study conducted by Qiu et al., ${ }^{[20]}$ coadsorption was used to improve the adsorption capacity of sulfamethoxazole (SMX) by a polyamine-modified resin in the presence of Copper. The results showed that the adsorption of SMX increased by $9.1 \%$ as a result of the bridging effect between the SMX molecules and the $\mathrm{Cu} I I$ ions. Thus more SMX was adsorbed as on the new sites created by the $\mathrm{Cu}$ II ions on the surface of the resin.

\section{Carbonaceous sorbents}

Carbonaceous sorbents are generally categorized as the activated carbon, carbon nanotube (CNTs), graphite, graphene oxide (GO), charcoal, and so forth. ${ }^{[10]}$ Their porous structure, high BET, and adsorption capacities for organic and inorganic pollutants have made its use widely applied for scavenging pharmaceuticals from water. Several carbonaceous materials with the different surface area have been reported for removal of antibiotics. ${ }^{[21]}$ The most important characteristics of carbonaceous sorbents are the ability to be synthesized with controlled structure and chemical features. The adsorption capacity of some carbonaceous material is shown in Table 2. Activated carbon is a dominantly studied sorbent that has been widely used for the investigation of antibiotics removal from water. Almost all carbonaceous materials can be used to produce activated carbon, but the properties vary with its raw materials and activation method. Physical, chemical, and physiochemical are the main techniques employed for the activation of carbon. ${ }^{[22]}$ Activated carbon possess well-developed structure and responsible for physical adsorption. ${ }^{[23]}$ Putra et al. ${ }^{[24]}$ studied the performance of activated carbon for adsorption of amoxicillin from wastewater; the physical structure of the activated carbon was confirmed to contain micropores and BET of $1092.951 \mathrm{~m}^{2} / \mathrm{g}$. The adsorption process was affected by $\mathrm{pH}$, temperature, the affinity of adsorbate to solvent, solution $\mathrm{pH}$, and adsorbent mass. However, the reaction was favorable at $\mathrm{pH} 4.98$, where the maximum adsorption $(221.868 \mathrm{mg} / \mathrm{g})$ for amoxicillin was achieved. Figure 1 describes the possible mechanism for the adsorption reaction and electrostatic force between the carboxyl functional group in the structure of the activated carbon and the amine group of the amoxicillin. Modification of activated carbon gives better adsorption capacity. It can be done physically, chemically, or thermally. Sellaoui et al. ${ }^{[25]}$ chemically modified activated carbons by iron benzoate and cobalt (MAC-1), and with iron oxalate and cobalt (MAC-2)

Table 2 Adsorption capacities of some carbonaceous sorbents

\begin{tabular}{ccccccc}
\hline Drug & Adsorbent & $\mathrm{pH}$ & $\begin{array}{c}\text { Temp./ } \\
{ }^{\circ} \mathrm{C}\end{array}$ & $\begin{array}{c}\mathrm{BET} / \\
\left(\mathrm{m}^{2} / \mathrm{g}\right)\end{array}$ & $\begin{array}{c}\text { Ad. cap./ } \\
(\mathrm{mg} / \mathrm{g})\end{array}$ & Ref. \\
\hline Amoxicillin & $\begin{array}{c}\text { ZnO/carbon } \\
\text { nanofibers }\end{array}$ & 7.5 & - & - & 156 & {$[21]$} \\
Amoxicillin & MAC-1 & - & 50 & - & 245.03 & {$[25]$} \\
Amoxicillin & MAC-2 & & 50 & - & 414.03 & {$[25]$} \\
Amoxicillin & AC & 4.98 & - & 1092.95 & 221.8 & {$[24]$} \\
Penicillin G & SWCNTs & 5 & 10 & - & 141 & {$[29]$} \\
Penicillin G & MWCNTs & 5 & 10 & - & 119 & {$[29]$} \\
Amoxicillin & MWCNTs & 7 & 60 & 712.9 & 159.4 & {$[33]$} \\
\hline
\end{tabular}




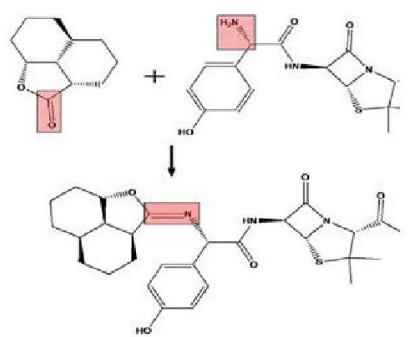

Figure 1 Reaction between carbonyl groups on activated carbon and amine functional groups on amoxicillin. ${ }^{\text {[2] }}$

to study the adsorption of amoxicillin. Modified adsorbents have a large number of functional groups in the structure, which facilitated the high adsorption. The adsorption process was endothermic, which suggests that the reaction is thermally governed. Thus, the adsorption capacity was seen to increase as the temperature increased (i.e., MAC-1, $25{ }^{\circ} \mathrm{C}-152.05$ $\mathrm{mg} / \mathrm{g} ; 50{ }^{\circ} \mathrm{C}-245.03 \mathrm{mg} / \mathrm{g}$ and MAC-2, $25{ }^{\circ} \mathrm{C}-245.03 \mathrm{mg} / \mathrm{g}$; $50{ }^{\circ} \mathrm{C}-414.03 \mathrm{mg} / \mathrm{g}$ ). The similar trend was observed in a study conducted by Moussavi et al. ${ }^{[26]}$ The authors conducted a test to compare the result of $\mathrm{NH}_{4} \mathrm{Cl}$-induced activated carbon (NAC) and standard activated carbon (SAC) test for removal of amoxicillin. The results revealed that NAC exhibited better adsorption properties $(437 \mathrm{mg} / \mathrm{g})$ and higher surface area (1029 $\mathrm{m}^{2} / \mathrm{g}$ ). The greater adsorption capacity of NAC can be related to the greater availability of sites, higher density of charge, and more surface functional group than on the surface of the SAC due to modification of NAC.

Carbon nanotubes (CNTs) are new adsorbents that have gained the attention of researchers. It was reported to be more efficient than activated carbons in the removal of some pharmaceutical drugs. ${ }^{[27]}$ CNTs can be classified into SWCNTs and MWCNTs. It is observed that SWCNTs are more efficient than MWCNTs. In an experiment conducted on MWCNT for amoxicillin removal, the adsorption capacity was reported to be $523 \mathrm{mg} / \mathrm{g} .{ }^{[28]}$ Furthermore, it was observed that SWCNTs and MWCNTs had an adsorption capacity of $141 \mathrm{mg} / \mathrm{g}$ and 119 $\mathrm{mg} / \mathrm{g}$ for removal of penicillin $\mathrm{G}$ from aqueous solution, respectively. ${ }^{[29]}$ Another study by Mohammadi et al. ${ }^{[30]}$ reported that the evaluation of the adsorbent capacity showed that each gram of MWCNTs could absorb $22.9 \mathrm{mg}$ amoxicillin. The adsorption of two antibiotics (lincomycin and sulfamethoxazole) by CNTs was in the order SWCNTs $>$ MWCNTs. ${ }^{[11]}$ These results suggest that SWCNTs are more efficient than MWCNTs, probably due to the higher exposed surface area and easily accessible pores compared to MWNT, which has a lower specific surface area. Balarak et al. ${ }^{[32]}$ investigated the feasibility of removing amoxicillin using MWCNTs. The MWCNTs sorbent was treated with nitric acid to create more oxygen functional group on the surface of the sorbent. The reaction was spontaneous and endothermic and adsorption capacity of $159.4 \mathrm{mg} / \mathrm{g}$. Another study was conducted by Balarak et al. ${ }^{[33]}$ to examine the adsorptive strength of magnetic MWCNT for removal of amoxicillin. The sorbent was synthesized by first treating in nitric acid and further modified by reacting in ferrous ammonium sulfate and of ammonium ferric sulfate to obtain MWCNT with magnetic properties and better adsorption capacity. The results revealed that the sorbents had deposits of iron oxide nanoparticles on its surface and better adsorption capacity $(395.5 \mathrm{mg} / \mathrm{g}$ ) for amoxicillin owing to the availability of more surface area for adsorption of amoxicillin by the iron oxide nanoparticles deposits. Similarly, the reaction was spontaneous and endothermic.

Graphene is made up of graphitic carbon sheets with a hexagonal structure of linked carbon atoms by $\mathrm{sp}^{2}$ bonds. Graphene exhibits excellent mechanical and physical properties. It can be converted into graphene oxide by chemical oxidation or can be used with other materials to produce graphene based materials or graphene oxide composites for the removal of antibiotics from water. ${ }^{[34]}$ Several graphene, graphene oxides and graphene based nanocomposites have been exploited for the removal of tetracycline ${ }^{[35]}$ doxycycline ${ }^{[36]}$ and so on. Rostamian et al. ${ }^{[37]}$ found that the adsorption of sulfameth-oxazole is more promoted on graphene oxide nanosheets (GOS) than graphene nanosheet (GNS). The author disclosed that the adsorption process is affected by $\mathrm{pH}$ and more favorable at a lower temperature. Thus the reaction is exothermic. It was revealed that the adsorption of tetracycline (TCN), doxycycline (DCN) onto GOS was also exothermic and optimum at $\mathrm{pH} 6-7$. The maximum adsorption capacity was in the order DCN>TCN. ${ }^{[36]}$

\section{Clay}

Clays are aluminosilicate minerals that exist in the layered structure of rock, carbonates, or silicates. They are cheap, abundant, and require less processing cost as adsorbents. Examples are the bentonite, vermiculite, etc. Vermiculite is clay containing a layer of alumina octahedral arranged in between two layers of silica. The arrangement allows water and other molecules to intercalate into the interlamellar space of the vermiculites, which makes it have adsorptive properties. The adsorption capacity of these adsorbents and other parameters are shown in Table 3. An experiment was carried out by Wang et al. ${ }^{[38]}$ using preheated and modified vermiculite for sorption of sulfamethoxazole (SMX). The heated vermiculite showed superior adsorption capacity in comparison to the raw vermiculite, which could be attributed to abundantly available sites. Moreover, the adsorption process followed a pseudo secondorder that agreed well with Freundlich isotherm. Bentonite consists mainly of montmorillonite and aluminum phyllosilicate and generally impure clay. This material has been exploited as an adsorbent due to its low cost, and abundance in nature. Bentonites have been greatly studied for the removal of amoxicillin, tetracycline, cephalexin, and ciprofloxacin from water. ${ }^{[39]}$ The potential of Bentonite to adsorb amoxicillin has been studied by Putra et al. ${ }^{[24]}$ revealed that the material had a BET of $91.627 \mathrm{~m}^{2} / \mathrm{g}$ and adsorption capacity of $49.9 \mathrm{mg} / \mathrm{g}$ at $30{ }^{\circ} \mathrm{C}$, $\mathrm{pH} 3.85$ for AMX. The low adsorption can be attributed to the low availability of sorption sites on the surface of the sorbent. Zha et al. ${ }^{[40]}$ modify bentonite with hexadecyl trimethyl ammonium (organobentonite DK1) for the removal of amoxicillin from aqueous solution. The sorbent had a low surface area of (3.79 $\mathrm{m}^{2} / \mathrm{g}$ ) in comparison to raw bentonite synthesized by Putra et al. ${ }^{[24]}$ The adsorption process was endothermic, however, the maximum adsorption capacity was low $\left(26.18 \mathrm{mg} / \mathrm{g}\right.$ at $\left.20^{\circ} \mathrm{C}\right)$, but increased to $45.07 \mathrm{mg} / \mathrm{g}$ when the initial concentration of $\mathrm{AMX}$ increased to $300 \mathrm{mg} / \mathrm{L}$ at temp $30{ }^{\circ} \mathrm{C}$. The adsorption capacity may increase at higher temperature since the reaction is endothermic. These results suggest that all modification may not produce better adsorption properties. Jin et al. ${ }^{[41]}$ experimented with comparing the adsorption capacity of DK1 and bentonites. The results revealed that the adsorption capacity of DK1 was six times greater than the raw bentonite. The BET surface area $3.79 \mathrm{~m}^{2} / \mathrm{g}$ and adsorption capacity of $33.51 \mathrm{mg} / \mathrm{g}$ at $40{ }^{\circ} \mathrm{C}$ temperature were reported for DK1. Similar to previous studies, the reaction was endothermic. Bentonite (Natural clay) and four-pillared clay with different pillaring agents silica pillared clay (Si-PILC), iron pillared clay (Fe-PILC), aluminum pillared clay (AI-PILC), and zirconium pillared clay (Zr-PILC) were investigated for the removal of ciprofloxacin. ${ }^{[39]}$ The pillared clays showed different behaviors according to the pillaring agents. The adsorption capacity was in the order Fe-PILC > Si-PILC $>$ NC $>$ Zr-PILC > Al-PILC. This adsorption behavior could be due to higher access of ciprofloxacin to the porous 
structure of Fe-PILC and Si-PILC in comparison to the other sorbents. The adsorption mechanism was described by innersphere complexes formation as well as van der Waals interactions. Genç et al. ${ }^{[42]}$ observed that the maximum adsorption capacity of ciprofloxacin adsorbed onto bentonite was 147.06 $\mathrm{mg} / \mathrm{g}$. Solution $\mathrm{pH}$ had a strong influence on the adsorption properties, and the reaction was best described using the Langmuir model. In another study, Genc and Dogan ${ }^{[43]}$ analyze the ciprofloxacin (CIP) sorption by bentonite, activated carbon, zeolite, and pumice. The adsorption capacity was in the order bentonite $>$ activated carbon $>$ zeolite $>$ pumice. Although activated carbon is well-known adsorbent with high surface area, low cost, and so on, ciprofloxacin adsorption capacity on bentonite was much higher, which suggests that bentonite may serve as an environmental sink for cationic drugs such as ciprofloxacin.

Table 3 Adsorption capacities of some clay based sorbents

\begin{tabular}{ccccccc}
\hline Drug & \multirow{2}{*}{ Adsorbent } & $\mathrm{pH}$ & $\begin{array}{c}\text { Temp./ } \\
{ }^{\circ} \mathrm{C}\end{array}$ & $\begin{array}{c}\mathrm{BET} / \\
\left(\mathrm{m}^{2} / \mathrm{g}\right)\end{array}$ & $\begin{array}{c}\text { Ad. cap./ } \\
(\mathrm{mg} / \mathrm{g})\end{array}$ & Ref. \\
\hline Amoxicillin & Bentonite & 3.8 & 30 & 91.6 & 49.9 & {$[24]$} \\
Amoxicillin & DK1 & - & 20 & 3.79 & 26.1 & {$[40]$} \\
Ciprofloxacin & Fe-PILL & 10 & 20 & 206 & 122 & {$[39]$} \\
Ciprofloxacin & Si-PILL & 10 & 20 & 519 & 100 & {$[39]$} \\
Ciprofloxacin & Clay & 10 & 20 & 67 & 80.8 & {$[39]$} \\
Ciprofloxacin & Zr-PILL & 10 & 20 & 231 & 25.2 & {$[39]$} \\
Ciprofloxacin & Al-PILL & 10 & 20 & 322 & 17.7 & {$[39]$} \\
Ciprofloxacin & Bentonite & 4.5 & - & - & 147 & {$[42]$} \\
\hline
\end{tabular}

\section{Miscellaneous sorbents}

Several types of adsorbent materials have been investigated for the removal of antibiotics from water as alternative adsorbents. They include waste materials, sludge, nano-hydroxyapatite, etc. Lignin based adsorbents were investigated by Gao et al. ${ }^{[44]}$ for the removal of fluoroquinolone (FQ) antibiotic, from water. Cross-linked lignin (LNEs) and carboxymethyl cross-linked lignin (LNECs) were synthesized and employed for ofloxacin adsorption. It was observed that the reaction was $\mathrm{pH}$ dependent with the maximum value reached at $\mathrm{pH} 6$ for LNEs and 7.0 for LNECs. Figure 2 describes the adsorption mechanism at different $\mathrm{pH}$ range. The study states that (LNEs) and (LNECs) can be efficient and environmental-friendly adsorbents for removal of FQs. Wang et al. ${ }^{[45]}$ tested the adsorption behavior of sulfamethoxazole (SMX) and ofloxacin (OFL) onto sediments. Rapid adsorption of SMX onto the sediment was reported. Hydrophobic and electrostatic interactions were the dominant adsorption mechanism of SMX and OFL on the sediments. Nielsen and Bandos $z^{[46]}$ found that the adsorption of sulfamethoxazole (SMX) and trimethoprim (TMP) on sewage sludge and fish waste-derived adsorbents were by surface chemistry. The authors reported that pure fish waste was more effective and the adsorption capacity for SMX at $950{ }^{\circ} \mathrm{C}$ pyrolysis was 31 times greater than on the same material pyrolized at $650{ }^{\circ} \mathrm{C}$. Moreover, there was a synergistic effect between the two wastes when mixed at $90 \%$ sewage sludge and $10 \%$ fish waste for adsorption of TMP. Hu and Wang ${ }^{[47]}$ observed that separated cellulose from flat oil-modified via grafting a cationic quaternary ammonium group (QCFN) to remove AMX from aqueous solution had a maximum adsorption capacity, which reached $183.14 \mathrm{mg} / \mathrm{g}$. The reaction was $\mathrm{pH}$-dependent and was more favorable as the solution $\mathrm{pH}$ increased. The results revealed that the adsorption was endothermic and spontaneous. $\mathrm{Li}$ et al. ${ }^{[48]}$ examined the effectiveness of peanut shells in removing four antibiotics sulfathiazole (ST), sulfamerazine (SM), sulfamethazine (SM2), and sulfamethoxazole (SMX) using

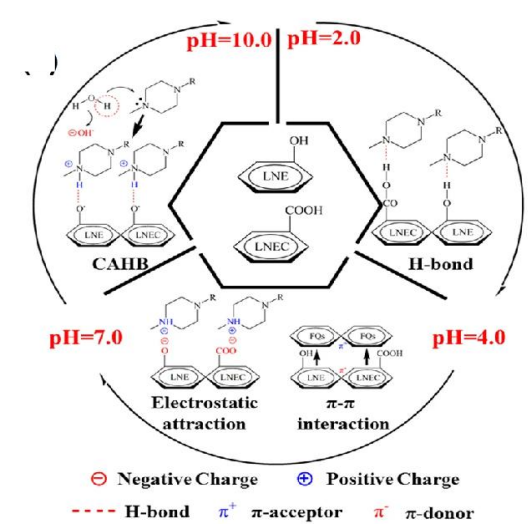

Figure 2 The possible adsorption mechanisms of lignin based adsorbent for ciprofloxacin at different $\mathrm{pH}$ conditions. ${ }^{[44]}$

batch adsorption test. The adsorption capacity of the four antibiotics decreased in the order $\mathrm{ST}>\mathrm{SM}>\mathrm{SM} 2>\mathrm{SMX}$. The results showed that the adsorption proceeded according to the henry linear adsorption model indicating that the adsorption is a partitioning process. Furthermore, the removal efficiency was also affected by the adsorbent dosage, initial concentration, and water hardness $\left(\mathrm{Fe}^{2+}, \mathrm{Mn}^{2+}\right.$, and $\left.\mathrm{Ca}^{2+}\right)$. Nano-hydroxyapatite $\left(\mathrm{Ca}_{10}\left(\mathrm{PO}_{4}\right)_{6}(\mathrm{OH})_{2}\right.$, nHAP), universal inorganic secondary metal minerals, was tested for the removal of oxytetracycline at four different $\mathrm{pH}^{[52]}$ The author observed rapid adsorption of oxytetracycline within the first $15 \mathrm{~min}$. The initial adsorption rates under four $\mathrm{pH}$ values followed an order of $\mathrm{pH} 8.0>$ $\mathrm{pH} 10.0>\mathrm{pH} 5.5>\mathrm{pH} 3.0$ with the strongest adsorption affinity at $\mathrm{pH}$ 8. Elovich and Freundlich models best described the adsorption.

\section{Conclusions}

The adsorption performance of polymeric substance, activated carbon, carbonaceous sorbents, and other sorbents for the removal of antibiotics, namely oxytetracycline, penicillin, ciprofloxacin, and others has been reviewed. The high adsorption capacity was reported for polymer sorbent towards penicillin $\mathrm{V}$ in comparison to the other reviewed sorbents. Polymeric adsorbents have been extensively used as potential alternatives to activated carbon. The polymer sorbent may be synthesized to suit the removal of the targeted antibiotics from aqueous. Generally, the adsorption of hydrophobic antibiotics on polymer sorbents has recorded low adsorption capacity. Antibiotics may adsorb on the surface of sorbent through the non-covalent bond, electrostatic attraction, and $\pi-\pi$ interaction. The effect of adsorption parameters of the reviewed sorbents on antibiotics shows that the effect of $\mathrm{pH}$, ionic strength, and temperature had a significant effect on the adsorption capacity. $\mathrm{pH}$ and ionic strength had the most significant effect on the adsorption of antibiotics on polymer sorbents. Among carbonaceous sorbents, bentonite, activated carbon and CNTs were found to be endothermic towards the adsorption of several antibiotics, while CNTs was exothermic for sulfamethoxazole. The unique structure of graphene-based materials causes a difference in its adsorption properties as compared to other carbonaceous sorbents. There was little or no significant difference in the adsorption capacity of modified bentonite for amoxicillin. However, bentonite has a greater affinity for ciprofloxacin than amoxicillin. SWCNTs possessed high adsorption capacity compared to MWCNTs. Several models have been used to describe the adsorption isotherm of antibiotics. The kinetic data on activated carbon for adsorption of antibiotics was well described using the pseudo-second-order model indicating chemisorption nature. Generally, the adsorption 
capacity of clay is low as compared to polymers and carbon sorbent. This is due to their lower BET surface area. However, they serve as alternatives to activated carbon and polymer sorbent because of its low cost and abundance in nature. But in the case of ciprofloxacin antibiotics, clay material (bentonite) has shown better adsorption qualities when compared to activated carbon. An increasing number of studies include the adsorption of antibiotics on polymers, carbonaceous, clay, and other waste-based sorbents. However, several points still need more attention, such as the effect of modification, salts, on the adsorption of antibiotics and regeneration of the tested adsorbents. Moreover, these studies have been carried out in a laboratory-scale and need to be tested more on real water samples or performed in an industrial scale.

\section{References}

[1] Gomes, R. A.; Justino, C.; Rocha-Santos, T.; Freitas, C. A.; Duarte, C. A.; Pereira, R. J. Environ. Sci. Health Part A-Toxic/Hazard. Subst. Environ. Eng. 2017, 24, 992.

[2] Tiwari, B.; Sellamuthu, B.; Ouarda, Y.; Drogui, P.; Tyagi, D. R.; Buelna, G. Bioresour. Technol. 2017, 224, 1.

[3] Klatte, S.; Schaefer, C. H.; Hempel, M. Sustain. Chem. Pharm. 2017, 5, 61.

[4] Kanakaraju, D.; Glass, B. D.; Oelgemöller, M. J. Environ. Manage. 2018, 219, 189.

[5] Wang, J.; Wang, S. J. Environ. Manage. 2016, 182, 620.

[6] Kumar, R.; Laskar, A.; Hewaidy, I. M. F.; Barakat, A. M. Earth Syst. Environ. 2019, 3, 83.

[7] Ahmad, A.; Setapar, M. H. S.; Chuong, S. C.; Khatoon, A.; Wani, A. W.; Kumar, R.; Rafatullah, M. RSC Adv. 2015, 5, 30801.

[8] Ahmad, A.; Siddique, A. J.; Laskar, A. M.; Kumar, R.; Khatoon, A.; Setapar, S. H. M. J. Environ. Sci. 2015, 31, 104.

[9] Gupta, K. V.; Kumar, R.; Nayak, A.; Barakart, A. M.; Saleh, A. T. Adv. Colloid Interface Sci. 2013, 191-193, 24.

[10] Akhtar, J.; Amin, N. A. S.; Shahzad, K. Des. Wat. Treat. 2015, 57, 1.

[11] Kumar, R.; Khan, A. M.; Haq, N. Environ. Sci. Technol. 2014, 9, 1000.

[12] Belaib, F.; Azzedine, M.; Boubeker, B.; Abdeslam-Hassen, M. Int. J. Hydrog. Energy 2014, 39, 1511.

[13] Zhou, Y.; Cheng, G.; Chen, K.; Lu, J.; Lei, J.; Pu, S. Ecotox. Environ. Safe. 2019, 170, 278.

[14] Pan, B.; Pan, B.; Zhang, W.; Lv, L.; Zhang, Q.; Zheng, S. Chem. Eng. J. 2009, 151, 19.

[15] Zhang, Y.; Ou, H. J.; Liu, H. X.; Ke, Y. L.; Zhang, W. J.; Liao, G. Y.; Wang, D. S. Colloids Surf. A 2018, 537, 92.

[16] Zhang, Y.; Cai, X.; Xiong, W.; Jiang, H.; Zhao, H. PLoS One 2014, 9, 86228

[17] Ribeiro, L. M.; Ribeiro, C. I. Bioproc. Biosyst. Eng. 2003, 26, 49.

[18] Li, J.; Zhang, K.; Zhang, H. Environ. Pollut. 2018, 237, 460.

[19] Chaubal, V. M.; Payne, F.G.; Reynolds, H. C.; Albright, L. R. Biotechnol. Bioeng. 1995, 47, 215.

[20] Qiu, H.; Ling, C.; Yuan, R.; Liu, F.; Li, A. Chem. Eng. J. 2019, 362, 422.

[21] Chaba, M. J.; Nomngongo, N. P. Emerg. Contam. 2019, 5, 143.

[22] Ahmed, J. M. Environ. Toxicol. Pharm. 2017, 50, 1.

[23] Ania, O. C.; Pelayo, G. J.; Bandosz, J. T. Adsorption 2011, 17, 421.
[24] Putra, K. E.; Pranowo, R.; Sunarso, J.; Indraswati, N.; Ismadji, S. Water Res. 2009, 43, 2419.

[25] Sellaoui, L.; Lima, C. E.; Dotto, L. G.; Lamine, B. A. J. Mol. Liq 2017, 234, 375.

[26] Moussavi, G.; Alahabadi, A.; Yaghmaeian, K.; Eskandari, M. Chem. Eng. J. 2013, 217, 119.

[27] Fazelirad, H.; Ranjbar, M.; Taher, A. M.; Sargazi, G. J. Ind. Eng. Chem. 2015, 21, 889.

[28] Bazregari, M.; Farhadian, N. Environ. Technol. 2017, 39, 2231.

[29] Chavoshan, S.; Maryam, K. M.; Nasseh, N.; Panahi, H. A.; Hosseinnejad, A. H. Environ. Health Eng. Manag. 2018, 5, 187.

[30] Mohammadi, A.; Kazemipour, M.; Ranjbar, H.; Walker B. R.; Ansari, M. Fuller. Nanotub. Carbon Nanostruct. 2015, 23, 165.

[31] Kim, H.; Hwang, Y. S.; Sharma, V. K. Chem. Eng. J. 2014, 255, 23.

[32] Balarak, D.; Mostafapour, F.; Bazrafshan, E.; Saleh, T. A. Water Sci. Technol. 2017, 75, 1599.

[33] Balarak, D.; Mostafapour, K. F.; Joghtaei, A. Br. J. Pharm. Res. 2017, 16, 1.

[34] Huízar-Félix, M. A.; Aguilar-Flores, C.; Martínez-de-la, Cruz. A.; Barandiarán, M. J.; Sepúlveda-Guzmán, S.; Cruz-Silva, R. Nanomaterials 2019, 9, 313.

[35] Ghadim, E. E.; Manouchehri, F.; Soleimani, G.; Hosseini, H.; Kimiagar, S.; Nafisi, S. PLoS One 2013, 8, 79254.

[36] Rostamian, R.; Behnejad, H. Ecotox. Environ. Safe. 2018, 147, 117.

[37] Rostamian, R.; Behnejad, H. Process Saf. Environ. 2016, 102, 20.

[38] Wang, J.; Gao, M.; Ding, F.; Shen, T. Colloids Surf. A 2018, 546, 143.

[39] Jalil, R. E. M.; Baschini, M.; Sapag, K. Materials 2017, 10, 1345.

[40] Zha, X. S.; Zhou, Y.; Jin, X.; Chen, Z. J. Environ. Manag. 2013 $129,569$.

[41] Jin, X.; Zha, S.; Li, S.; Chen, Z. Appl. Clay Sci. 2014, 102, 196.

[42] Genç, N.; Dogan, E. C. Yurtsever, M. Water Sci. Technol. 2013, 68, 848.

[43] Genç, N.; Dogan, C. E. Desalin. Water Treat. 2015, 53, 785.

[44] Gao, B.; Li, P.; Yang, R.; Li, A.; Yang, H. Sci. Rep. 2019, 9, 637.

[45] Wang, P.; Zhang, D.; Zhang, H.; Li, H.; Ghosh, S.; Pan, B. Chemosphere 2017, 175, 123.

[46] Nielsen, L.; Bandosz, J. T. Micropor. Mesopor. Mat. 2016, 220, 58

[47] Hu, D.; Wang, L. J. Taiwan Inst. Chem. E 2016, 64, 227.

[48] Li, L.; Zhang, Y.; Chu, W.; Chen, Z.; Wang, W. RSC Adv. 2018, 8, 13546.

[49] Itodo, A. U.; Eneji, I. S.; Weor, T. T. J. Chem. Soc. Nigeria 2018, 43, 667.

[50] Dutta, M.; Dutta, N. N.; Bhattacharya, G. K.; Sep. Purif. Technol. 1999, 16, 213.

[51] Zhang, H.; Wang, J.; Zhou, B.; Zhou, Y.; Dai, Z.; Zhou, Q.; Chriestie, P.; Luo, Y. Environ. Pollut. 2018, 243, 1550.

[52] Yuan, L.; Yan, M.; Huang, Z.; He, K.; Zeng, G.; Chen, A.; Hu, L.; Li H.; Peng, M.; Huang, T.; Chen, G. J. Colloid Interface Sci. 2019 $541,101$.

[53] Sadegh, H.; Ali, G. A. M.; Gupta, V. K.; Makhlouf, A. S. H.; Shahryari-ghoshekandi, R.; Nadagouda, M. N.; Sillanpää, M.; Megiel, E. J. Nanostruct. Chem. 2017, 7, 1.

Received August 9, 2019 Accepted September 10, 2019 